\title{
Chronic respiratory disease - the acceptable epidemic?
}

\author{
Author: Peter Burney ${ }^{\mathrm{A}}$
}

\begin{abstract}
Chronic obstructive pulmonary disease (COPD) is a major cause of disability and death in the UK but is an even greater problem in low income countries. It is assumed by many to be almost entirely attributed to smoking. However, smoking alone cannot account for the distribution of the disease in the world and there is accumulating evidence that the disease is overwhelmingly a disease of poverty. The size of the problem and the failure of current hypotheses to explain the distribution of chronic lung disease make the lack of funding in this area surprising. The failure of science funders to respond to the analysis of the Cooksey report, which pointed out the extreme discrepancy between the size of the problem and the paucity of research funding, represents a serious failure in science policy. The lack of urgency in the face of such a large burden of illness suggests a degree of complacency in the face of a disease that is overwhelmingly a disease of the poor.
\end{abstract}

KEYWORDS: COPD, disease burden, lung function, policy, poverty

Those afflicted are inclined to accept the complaint as inevitable, as something troublesome but not serious. Those called upon to treat it do not find it sufficiently interesting to study closely... Yet bronchitis stands high not only in the list of causes of death, but also among causes of invalidity... Records in England and Wales show that when mortality and morbidity are taken together, bronchitis is the most important of all diseases; and ... at the same time a most preventable disease E L Collis, Mansel Talbot Professor of Preventive Medicine, Cardiff. ${ }^{1}$

\section{Introduction}

This paper addresses the problem of why chronic obstructive pulmonary disease (COPD) is so poorly understood and yet so little researched. There are two valid reasons for ignoring a subject as a research topic; the first is that the problem is unimportant and the second is that all the important questions have satisfactory answers. Neither of these two excuses justifies the current neglect of chronic respiratory disease. By any

Author: A senior research fellow, National Heart and Lung Institute, Imperial College, London, UK measure, COPD is a major health problem. In 2010, COPD was ranked third as a cause of death globally ${ }^{2}$ and fifth in years of life lived with disability, ${ }^{3}$ and even a cursory review of its distribution shows that this is not adequately explained by our current understanding of the condition.

\section{The British hypothesis}

Up until the mid-1970s the generally held view was that inhaled irritants - mostly cigarette smoke and smoke from domestic chimneys - led to chronic mucus hypersecretion, which in turn led to infective episodes, destruction and scarring of the lungs and airflow obstruction. According to this account, damage eventually led to respiratory failure and death. However, Charles Fletcher - who had been largely responsible for elaborating this 'British hypothesis' - subsequently showed that there was very little association between the exacerbations of disease in men with chronic bronchitis and the decline in their lung function. ${ }^{4}$ Some years later, Richard Peto, Charles Fletcher and others also showed that mortality in a number of occupational cohorts was strongly associated with the 1-second forced expiratory volume $\left(\mathrm{FEV}_{1}\right)$ but that it was not associated with the presence of chronic mucus hypersecretion when the association with ventilatory function had been taken into account. $^{5}$

Not everyone has fully accepted the passing of the British hypothesis. In particular, it has been argued that the role of mucus is still important in the later stages of disease. ${ }^{6}$ However, its role is generally seen as secondary and the role of ventilatory function has taken centre stage.

\section{A new orthodoxy}

Much of the new orthodoxy is very similar to the old. Apart from having no central role for mucus hypersecretion, the rest of the hypothesis remains intact. Inhaled irritants cause inflammation, which causes lung damage and airflow obstruction, eventually leading to respiratory failure and death. There have, however, been two further elaborations. The observation that low lung function has been associated with total all-cause mortality and with cardiovascular mortality has led to a more intense interest in the link between COPD and comorbidities, ${ }^{7}$ and David Barker's observation that deaths from COPD and low lung function were associated with early life factors, including birth weight, childhood infections and weight gain in the first year of life, has led to a greater interest in possible developmental influences on the aetiology of COPD. ${ }^{8}$ 
This perspective has some points in common with what Charles Fletcher named the 'Dutch hypothesis', which suggested a common origin for airway obstruction in both asthma and COPD.

\section{Explaining deaths from COPD}

The comparative distribution of deaths attributed to COPD and the known risk factors for airflow obstruction casts doubt on the current theories. Mortality rates from COPD are high in regions like South Asia and South-East Asia where smoking is relatively rare and are comparatively rare in Eastern Europe where smoking has been widespread. Salvi and Barnes ${ }^{9}$ have suggested that the discrepancy can be explained by exposure to biomass burning on cooking stoves. If this is true, however, it is not occurring through increased airflow obstruction. When measured using spirometry, the prevalence of airflow obstruction (a low $\mathrm{FEV}_{1}$ / forced vital capacity (FVC) ratio) is rare in most of South and South-East Asia and correlates reasonably well with the smoking histories of the population. ${ }^{10}$ More generally, the distribution of airflow obstruction does not correlate well with mortality rates attributed to COPD. There is a much better correlation with regions that have a low vital capacity.

\section{The central importance of lung size}

When John Hutchinson invented his spirometer and described the vital capacity he did so in the belief that the total volume of air that a person could take in and expel from their lungs in a single breath would be a good predictor of longevity. The new instrument was designed to help the life assurance industry in assessing risk and setting premiums, and for almost a century research on ventilatory function was largely focused on the measurement of vital capacity. ${ }^{11}$ By the middle of the 20th century, interest had moved to obstructive lung disease and the measurement of flow rates such as the $\mathrm{FEV}_{1}$. Unfortunately, in many of the studies undertaken, the $\mathrm{FEV}_{1}$ was taken as a measure of obstruction without any adjustment for lung size and this has led to confusion.

If the FVC is important, a low $\mathrm{FEV}_{1}$, unadjusted for the FVC with which it is strongly correlated, cannot be interpreted as a measure of obstruction, and where the FVC or the VC has been measured, Hutchinson's original hunch has been vindicated. ${ }^{12}$ It has been shown that the FVC and not the $\mathrm{FEV}_{1} / \mathrm{FVC}$ ratio is the main determinant of longevity. ${ }^{13}$ Among older patients, the more complete assessment of lung volume (the total lung capacity) has been shown to be an even better predictor of mortality. ${ }^{14}$ Nevertheless, the associations of longevity, cardiovascular risk factors and inflammatory markers with a low $\mathrm{FEV}_{1}$ have frequently been mistaken for links with airflow obstruction. ${ }^{7}$

The realisation that it is the size of the lung and not the size of the airway that is at the centre of the problem opens up a whole new set of issues that have received very little attention. Measurement of lung volumes is more difficult than measurement of flow, particularly in community settings and even more so in low income settings. Little is known about the determinants of lung size, making preventive measures a very distant prospect, and almost nothing is known about how best to manage the condition.

\section{Problems of measurement}

The spirometer remains the main instrument used for assessing ventilatory function but has important limitations. The tests are dependent on effort and many individuals, particularly those who are sick, are unable to provide good test results. Even specialist units often provide poor data unless there is strict ongoing quality assurance, ${ }^{15,16}$ and this is particularly true for measures of FVC. Plethysmography is expensive and requires equipment that needs maintenance and is not portable. Methods using gas dilution have become more portable but remain expensive and methods using imaging are either expensive or time consuming.

\section{Problems of interpretation}

There are several areas of confusion or uncertainty in interpreting spirometric measurements. The most contentious has been the relationship between lung size and ethnicity. ${ }^{17}$ Vital capacity is known to be lower in those from ethnic backgrounds originating outside of Europe but how to use and interpret this information is controversial. Some view this as a normal variation with no clinical relevance and recommend that separate 'standards' are set for different ethnic groups. In a clinical setting where the question is whether an individual is likely to have an ongoing pathology, there is some justification for this. From a public health perspective, however, it is problematic.

First there is evidence that social conditions are associated with lung volumes ${ }^{18}$ and a clear possibility that some part of the low lung function seen in ethnic minority groups may be due to this. Second, regardless of the origins of the difference there is evidence that it carries a disadvantage independent of ethnicity. In an analysis of the Atheroma Risk in Communities (ARIC) study, the increased mortality in African Americans could be explained by their lower FVC; adjusting for ethnicity simply added an unexplained increase in mortality to the disadvantaged group. ${ }^{19}$

\section{The origins of low lung volumes}

If a common standard for low lung volume is adopted, a high prevalence of low FVC is almost the norm in the poorer countries of Asia and Africa, and is related to the development of the national economy as represented by the gross national income per capita. ${ }^{10}$ The association with a low income could be due to many intermediate conditions, or could be a coincidental finding explained by confounding. A better understanding of this link might provide more effective programmes for preventing the condition.

Currently, very little of the variation in FVC is explained. Family studies suggest that around $40 \%$ of variation is due to genetic factors, even in ethnically homogeneous groups. ${ }^{20}$ However, large genome-wide association studies have been able to identify genes that explain only a very small part of this. ${ }^{21}$ There is consistent evidence for a link with birth weight ${ }^{22}$ and there is some evidence of an association with markers of socio-economic prosperity. ${ }^{18}$ More specifically, a small increase in FVC has been reported among children in a low income setting whose mothers had taken part in a trial of high-dose Vitamin $\mathrm{A},{ }^{23}$ although another trial using a lower dose as part 
of a multi-vitamin supplementation programme showed no such effect. ${ }^{24}$

\section{Poverty and death}

The link between poverty and deaths attributed to COPD is strong, but not easy to interpret. In addition to the crosssectional association between poverty and COPD mortality, there is a strong association between regional changes in the gross national income and changes in the mortality from COPD. This is less easily confounded than an association in a cross-sectional study and the confounders that might explain the association need to be much more closely associated with poverty itself. For instance, the link between poverty and mortality in the longitudinal analysis is unlikely to be due to confounding by ethnicity although this could otherwise explain the purely cross-sectional association. The changes in mortality have been rapid over the last two decades and such a close association is unlikely to be explained by changes in early life - the most likely determinants of lung volumes in adult life according to other evidence. Given the lack of any good treatments, it is also unlikely to be due to improvements in the management of the condition itself although some could be due to improvements in the management of comorbid conditions.

\section{Implications for science policy}

Chronic respiratory disease is a major cause of death and disability in the world and its importance was recognised by the United Nations General Assembly as one of the four principal non-communicable diseases - 'cardiovascular diseases, cancers, chronic respiratory diseases and diabetes ${ }^{25}$ but activity in this area is minimal compared with that in the other three areas.

This gap in research was already clearly identified in the UK in 2006. In March of that year, the Chancellor of the Exchequer and the government invited Sir David Cooksey to undertake an independent review to advise on the best design and institutional arrangements for the public funding of health research in the UK. Among other analyses, Sir David looked at the relation of funding for different clinical areas compared to the amount of associated death and disability. Respiratory disease was a clear outlier, contributing much to the morbidity of the population but receiving little in research funding. ${ }^{26} \mathrm{~A}$ more recent review of this balance has suggested some progress in that the percentage of the research spend attributable to respiratory disease had increased by $89 \%$ while the total spend attributable to all specific clinical areas increased by $72 \%{ }^{27}$ Although this sounds like progress, it represents an increase from $0.9 \%$ to $1.7 \%$ and much of the 'additional funding' was a re-branding of the funds that went to universities to support the universities' contribution to research. More importantly, the absolute gap in funding for research on respiratory disease, between funding proportional to morbidity and actual funding, rose from $\mathfrak{E} 49$ million to $\mathfrak{E} 72$ million. Such a failure to change spending patterns at a time of rising budgets is due either to a deliberate disregard of the policy objectives implied in the Cooksey report or, more plausibly, to a lack of any effective mechanism for delivering on policy objectives. Neither interpretation is flattering to the current state of science policy.

\section{Understanding the failure in science policy}

In a recent review of this situation, a number of explanations from funders are quoted, including the view that the respiratory community is poor at collaboration, unhelpful when refereeing colleagues' submissions for funding and fails to speak with one voice. ${ }^{28}$ Other familiar excuses are that the applications for funds are not forthcoming or are of poor quality. These excuses cover a long history of disinterest and neglect of the subject. Chronic respiratory disease is a disease of the poor and has been of little interest to those that make funding decisions. The problem was highlighted in Sir David Cooksey's report and in the UN General Assembly's resolution but science policy and investment have remained unchanged. Scientific advance in the understanding of chronic lung disease has been disappointing, but science policy in this area has been an abject failure; this contrasts with areas such as Ebola research that have been perceived to pose only a small threat to middle-class lives in the USA and Europe.

When I was a student, it was assumed that the lack of interest in COPD was because everyone knew the cause to be smoking and the only question was how best to get people to give up smoking. As is clear from the quotation from Professor Collis, the neglect was apparent long before cigarettes were even under suspicion. The real enemy, as he suggested, has been indifference and an unwillingness to invest in a solution.

Much of the research that has been funded has been based on important misunderstandings about the nature of the condition that could have been avoided if there had been more effort to collect high-quality descriptive data in sufficient quantity. Other misunderstandings include a seemingly indestructible optimism that the next biomedical technology will provide a simple answer to any medical problem, regardless of how poorly it has been defined, and a minimal understanding about the design of clinical studies outside of randomised clinical trials. Training in 'clinical research' now amounts to little more than training in laboratory research for graduate students with medical degrees.

The problem identified by Professor Collis almost 100 years ago can still be remedied but only by a more proactive stance from policymakers and funders. I am not holding my breath. Chronic respiratory disease remains, for the moment, an acceptable epidemic.

\section{Conflicts of interest}

The author has no conflicts of interest to declare.

\section{Acknowledgements}

I am grateful to the Royal College of Physicians for the opportunity to give the Milroy Lecture for 2015, on which this article is based. I am grateful to Professor Neil Pride for drawing my attention to the paper by Professor Edgar Collis that is quoted at the beginning of the article. By coincidence Professor Collis gave the Milroy Lecture in 1915, exactly 100 years earlier.

\section{References}

1 Collis EL. The general and occupational prevalence of bronchitis and its relation to other respiratory diseases. J Ind Hygiene 1923;5:264-76 
2 Lozano R, Naghavi M, Foreman K et al. Global and regional mortality from 235 causes of death for 20 age groups in 1990 and 2010: a systematic. Lancet 2013;380:2095-128.

3 Vos T, Flaxman AD, Naghavi M et al. Years lived with disability (YLDs) for 1160 sequelae of 289 diseases and injuries 1990-2010: a systematic analysis for the Global Burden of Disease Study 2010. Lancet 2012;380:2163-96.

4 Fletcher C, Peto R. The natural history of chronic airflow obstruction. Br Med J 1977;1:1645-8.

5 Peto R, Speizer FE, Cochrane AL et al. The relevance in adults of air-flow obstruction, but not of mucus hypersecretion, to mortality from chronic lung disease. Results from 20 years of prospective observation. Amer Rev Respir Dis 1983;128:491-500.

6 Vestbo J, Hogg J. Convergence of the epidemiology and pathology of COPD. Thorax 2006;61:86-8.

7 Fabbri L, Rabe K. From COPD to chronic systemic inflammatory syndrome? Lancet 2007;370:797-9.

8 Barker DJ. The intrauterine origins of cardiovascular and obstructive lung disease in adult life. J Roy Coll Physicians of London 1991;25:129-33.

9 Salvi S, Barnes P. Chronic obstructive pulmonary disease in nonsmokers. Lancet 2009;374:733-43.

10 Burney P, Jithoo A, Kato B et al. Chronic Obstructive Pulmonary Disease Mortality and Prevalence: the associations with smoking and poverty - a BOLD analysis. Thorax 2014;69:465-73.

11 Myers JA. Vital Capacity Of The Lungs. Baltimore: Williams \& Wilkins, 1925.

12 Fried LP, Kronmal RA, Newman AB et al. Risk factors for 5-year mortality in older adults: the Cardiovascular Health Study. JAMA 1998;279:585-92.

13 Burney PGJ, Hooper R. Forced vital capacity, airway obstruction and survival in a general population sample from the USA. Thorax 2011;66:49-54.

14 Pedone C, Scarlata S, Chiurco D et al. Association of reduced total lung capacity with mortality and use of health services. Chest 2012;141:1025-30.

15 Enright PL, Johnson LR, Connett JE, Voelker H, Buist AS. Spirometry in the Lung Health Study. 1. Methods and Quality Control. Am Rev Respir Dis 1991;143:1215-23.

16 Müller-Brandes C, Krämer U, Gappa M et al. LUNOKID: can numerical American Thoracic Society/European Respiratory Society quality criteria replace visual inspection of spirometry? Eur Respir J 2014;43:1347-56.
17 Braun L, Wolfgang M, Dickersin K. Defining race/ethnicity and explaining difference in research studies on lung function. Eur Respir J 2013;41:1362-70.

18 Hegewald M, Crapo R. Socioeconomic status and lung function. Chest 2007;132:1608-14.

19 Burney PGJ, Hooper RJ. The use of ethnically specific norms for ventilatory function in African-American and white populations. Int J Epidemiol 2012;41:782-90.

20 Hukkinen M KJ, Broms U, Viljanen A et al. Heritability of lung function: a twin study among never-smoking elderly women. Twin Res Hum Genet 2011;14:401-7.

21 Obeidat M, Wain LV, Shrine $\mathrm{N}$ et al. A comprehensive evaluation of potential lung function associated genes in the SpiroMeta general population sample. PLoS ONE 2011;6:e19382.

22 Canoy D, Pekkanen J, Elliott P et al. Early growth and adult respiratory function in men and women followed from the fetal period to adulthood. Thorax 2007;62:396-402.

23 Checkley W, West JKP, Wise RA et al. Maternal Vitamin A supplementation and lung function in offspring. $N$ Engl J Med 2010;362:1784-94.

24 Devakumar D, Stocks J, Ayres JG et al. Effects of antenatal multiple micronutrient supplementation on lung function in mid-childhood: follow-up of a double-blind randomised controlled trial in Nepal. Eur Respir J 2015;45:1566-75.

25 United Nations. Political Declaration of the High-level Meeting of the General Assembly on the Prevention and Control of Noncommunicable Diseases. A/RES/66/2. United Nations, 2012. www. who.int/nmh/events/un_ncd_summit2011/political_declaration_ en.pdf [Accessed 19 July 2016].

26 Cooksey SD. A review of UK health research funding. London: HMSO, 2006.

27 UK Clinical Research Collaboration. UK Health Research Analysis 2009/10. London: UK Clinical Research Collaboration, 2012.

28 Snell N, Jarrold I, Holgate S. The current state of respiratory research in the UK. Thorax 2015;70:1011-13.

Address for correspondence: Dr P Burney, National Heart and Lung Institute, Emmanuel Kaye Building, Imperial College,

London SW3 6LR, UK.

Email: p.burney@imperial.ac.uk 